\title{
Los fundamentos políticos de la Restauración en Benito Pérez Galdós*
}

\author{
Political Basis of Spanish Restoration \\ in Benito Pérez Galdós
}

\author{
ROBERTO VILLA GARCÍA \\ Universidad Rey Juan Carlos \\ Facultad de Ciencias Jurídicas y Sociales \\ Departamento de Ciencias de la Educación, Lenguaje, Cultura y Artes, \\ Ciencias Historico-Jurídicas y Humanísticas y Lenguas Modernas \\ Campus de Madrid \\ Paseo de los Artilleros \\ 29032 Madrid (España) \\ roberto.villa@urjc.es
}

iD

RECIBIDO: FEBRERO DE 202

ACEPTADO: MARZO DE 2021

Resumen: Este artículo analiza las convenciones constitucionales del régimen de la Restauración en la obra de Benito Pérez Galdós. Se hace a través de dos de sus escritos fundamentales: la última novela de la quinta serie de los Episodios Nacionales, titulada Cánovas, y las crónicas parlamentarias que Galdós envió a La Prensa de Buenos Aires. Se trata la evolución doctrinal del autor desde el liberalismo constitucional al republicanismo regeneracionista a través de la plasmación galdosiana de aquel sistema político, y se muestra el valor desigual como fuente histórica de su obra periodística y literaria, a favor de la primera. Sin embargo, la mayor difusión de esta última contribuyó a reforzar una visión distorsionada de la Restauración que sirvió para legitimar la crítica republicana durante la última década de la monarquía liberal, y que se proyectaría después de 1923 en los movimientos políticos que afirmaron su legitimidad en la descalificación del liberalismo.

Palabras clave: España. Siglo XIX. Restauración. Monarquía constitucional. Benito Pérez Galdós. Antonio Cánovas del Castillo. Práxedes Mateo Sagasta.

Abstract: This article analyzes the constitutional conventions of the Restoration regime in the literary work of Benito Pérez Galdós. It does so through two of his fundamental writings: the last novel of the fifth serie of the Episodios Nacionales, entitled Cánovas, and the parliamentary chronicles that Galdós sent to La Prensa de Buenos Aires. The author's doctrinal evolution from constitutional liberalism to regenerationist republicanism is verified through the Galdosian analysis of that political system, and the different value as historical sources of his work as a journalist and as a writer is shown, in favour of the first. However, the greater diffusion of the latter contributed to streghten a distorted analysis of the Restoration that served to legitimize republican criticism during the last decade of that liberal monarchy, and that would be projected beyond 1923 in all those political movements that affirmed its legitimacy in the disqualification of liberalism.

Keywords: Spain 19th Century. Spanish Restoration. Constitutional Monarchy. Benito Pérez Galdós. Antonio Cánovas del Castillo. Práxedes Mateo Sagasta

\footnotetext{
* Esta investigación se inscribe en el marco del proyecto «Práctica electoral y quiebra del constitucionalismo en España, 1923 y 1936» (Comunidad de Madrid-Universidad Rey Juan Carlos, Ref. v792-PEQCE). 
En el capítulo final de Cánovas, la novela que cierra la quinta serie de los Episodios Nacionales, Benito Pérez Galdós hacía un balance desesperanzador de la Restauración a través de la musa de la Historia, Mariclío. Esta anticipaba al cronista Tito Liviano, protagonista de la serie y contrafigura del propio Galdós', que el advenimiento de Alfonso XII inauguraba «los tiempos bobos», una normalidad frívola y decadente que no merecía ser registrada. Esta normalidad venía contraindicada por el hecho de que, a diferencia de otros países «definitivamente constituidos», la España galdosiana era un «solar desgraciado» que no había llevado a su legislación «ni siquiera la libertad del pensar y del creer». En estas condiciones, la paz no era un don sino un mal, pues solo reflejaba la «pereza» y la «incapacidad» de la «raza», una «lenta parálisis» que llevaría a la «consunción» y a la «muerte» de la nación española.

La profecía de Mariclío reflejaba el balance pesimista que Galdós hacía de aquella monarquía constitucional en 1912, treinta y ocho años después de establecida. «Los políticos» se habían constituido en una «casta» dividida, hipócritamente, en «dos bandos» tan «dinásticos» como «estériles», que se limitaban a disputarse el presupuesto y otros recursos de la administración pública. No habían creado una nación, no habían fomentado la agricultura en las «estepas castellanas y extremeñas», ni remediado «el malestar de las clases proletarias». El dinero público lo consumía el gasto militar y las «pompas regias», no el fomento de la educación, la industria y el comercio. Lo peor era que aquellos políticos habían puesto «la enseñanza, la riqueza, el poder civil, y hasta la independencia nacional» en manos del Vaticano y la Iglesia española. Frente a todo ello, solo cabía promover una «revolución». Ser «revolucionario», contumaz en la rebeldía, era «el único síntoma de vida» en aquella España moribunda².

Este balance sombrío y la apelación a la táctica revolucionaria tan en boga antes de 1875 evidenciaban la evolución política que había llevado a Galdós a un republicanismo lindante con el socialismo, menos dispuesto a transigir con la realidad política en la que vivía. Contrastaba con su liberalismo del último cuarto del XIX, afín a Sagasta, y que se había reflejado en una valoración más positiva de la Restauración, sin apasionamientos y sobre todo por contraste con las vivencias de Galdós durante el Sexenio que la precedió. Por supuesto, también influía el género literario. Este examen desapasionado no se había plasmado en una novela sino a través de las crónicas que, en forma de carta, envió a La Prensa de Buenos Aires. La crónica periodística demandaba que cualquier valoración se sostuviera en una descripción y análisis que, dirigida además a lectores ajenos a la realidad española, debía maximizar lo informativo.

\footnotetext{
I Gullón, I987, p. 235.

2 Pérez Galdós, 1912, p. 278.
} 


\section{LOS FUNDAMENTOS POLÍTICOS DE LA RESTAURACIÓN}

Este artículo trata los distintos enfoques galdosianos sobre el sistema político de la Restauración. Parte de la necesidad de contextualizar los textos literarios que suelen usarse como fuente histórica para reconstruir y dar un sentido al universo de prácticas políticas del pasado. Los escritos de Galdós han sido una valiosa cantera por su observación penetrante de la realidad y el manantial de indicios que contiene sobre la articulación de las relaciones políticas, y también como reflejo de la estructura y la evolución de las mentalidades y de las representaciones colectivas de lo político. No obstante, la mayor difusión de sus novelas, y la adscripción del autor al realismo literario, las ha privilegiado respecto del género periodístico, que Galdós cultivó con provecho hasta constituirse en maestro de los cronistas parlamentarios. Aquí se defiende que las narrativas puramente literarias no son espejos fieles de la realidad, pues entretejen una constelación de imágenes propias que desembocan en simulaciones no siempre verosímiles. El contraste de las crónicas de La Prensa bonaerense con el Cánovas servirá para separar las informaciones históricas valiosas de aquellas convenciones y códigos de lenguaje y también de la mediatización artística de la realidad propias de los textos puramente literarios, con el fin de sortear las distorsiones hiperbólicas del pasado y las generalizaciones equívocas de hechos particulares ${ }^{3}$. Solo así la literatura, y especialmente una obra de la calidad de la novela galdosiana, puede otorgarnos claves fundamentales para entender mejor la vida política de la España anterior a la democratización. Por último, el artículo servirá para ilustrar los puntos de contacto entre el liberalismo progresista y el republicanismo, que engarzó como nadie el demócrata y anticlerical Galdós. La peculiaridad del personaje radica en que fue de las pocas figuras de su época que salió de las lindes del liberalismo constitucional y monárquico para convertirse en referente de la conjunción republicano-socialista. En la política activa de su tiempo, lo característico era hacer el camino contrario. Antes, sin embargo, es necesaria una somera revaluación del objeto que queremos estudiar a través de Galdós: los fundamentos políticos del sistema de la Restauración.

\section{EL SISTEMA POLÍTICO DE LA RESTAURACIÓN}

Los análisis sobre la monarquía liberal instaurada en 1875 son incontables y excelentes. No se pretende aquí volver sobre ellos, sino registrar aquellas convenciones constitucionales que aparecerán con recurrencia en la obra galdosiana. Se trata de entender el contraste entre la realidad de aquel régimen, las imágenes

\footnotetext{
${ }^{3}$ Ver al respecto las advertencias de Laslett, 1976, p. 321.
} 


\section{ROBERTO VILLA GARCÍA}

creadas por el Galdós novelista y las descripciones y valoraciones del Galdós cronista 4 .

El periodo de la Restauración se abrió el 3 I de diciembre de 1874 con la formación de un ministerio-regencia presidido por Antonio Cánovas del Castillo. Cánovas orientó el pronunciamiento militar de Martínez-Campos, aceptado por el resto del Ejército, a la restauración de la dinastía histórica en la figura de Alfonso XII, su cabeza visible desde que Isabel II renunciara los derechos al trono español en 1872. Pero al mismo tiempo, Cánovas pretendía dar una salida constitucional a la dictadura republicana del general Serrano, el régimen de excepción en el que había desembocado el proceso revolucionario abierto en 1868. Ese régimen, aunque había superado la crisis cantonalista, combatía entonces con poca fortuna las rebeliones del carlismo y el independentismo cubano.

La monarquía restaurada supuso el retorno al sistema de la doble confianza que había imperado antes de 1873 pero, a inspiración de Cánovas y los alfonsinos, con un mayor énfasis en la adopción de las convenciones del gobierno parlamentario a la inglesa, al menos tal y como este venía practicándose desde la Reform Act de 1832. Aprobada la Constitución de 1876, transacción entre los modelos constitucionales de 1845 y 1869 , el fundamento real del sistema residía en la convención no escrita de que el monarca debía llamar a gobernar sistemáticamente al jefe de la mayoría parlamentaria o, si determinadas circunstancias impedían su acceso al poder, a quien este indicara en las consultas que solían evacuarse durante las crisis de gobierno, que servían para descargar en los consejeros la responsabilidad de la decisión final del rey. Como aclaraba Cánovas en las Cortes, la realidad del gobierno parlamentario no admitía «que por punto general el Monarca se separe de lo que le proponen los Cuerpos colegisladores» ${ }^{5}$. De esta manera, la libertad que el artículo 54 de la Constitución de 1876 daba al rey para nombrar al presidente del Consejo de Ministros no se entendía como la de un monarca cabeza del poder ejecutivo que seleccionaba a sus «secretarios del despacho», sino como la libertad de un árbitro que debía solventar los choques del resto de los poderes, y especialmente los conflictos entre el ejecutivo y el legislativo. El Consejo de Ministros se convirtió, así, en el enlace entre la Corona y las Cortes, y en la instancia que permitía cumplir el artículo 18 de la Constitución, que prescribía que la ley naciera de la colaboración de ambas instancias. De ahí que, mientras en las monarquías como la alemana o la sueca sus reyes personalmente seleccionaban y presidían a sus ministros, generalmente altos funcionarios

\footnotetext{
${ }^{4}$ Para la cuestión que aquí se aborda son básicos los estudios de Varela Ortega, 200la; Dardé, 2003; y los trabajos reunidos en Tusell y Portero, 1997; y Varela Ortega, 200 Ib.

${ }^{5}$ Diario de Sesiones del Congreso (DSC), 15 de junio de $1880,4884$.
} 


\section{LOS FUNDAMENTOS POLÍTICOS DE LA RESTAURACIÓN}

de la administración ascendidos por la sola voluntad del monarca, en las monarquías como la española, que imitaron el modelo británico, sus gobiernos estuvieron compuestos de hombres de partido hechos en el Parlamento y escogidos y liderados por su propio jefe de filas, que era nombrado presidente con bastante automatismo ${ }^{6}$.

Por entonces, aún no era realidad el acuerdo entre conservadores y liberales que alumbraría el turno de ambos partidos. De hecho, los segundos no existieron como partido unificado hasta 1880 . Por ello, las segundas elecciones de la Restauración en 1879 se celebraron con los conservadores en el poder, aunque no con un gobierno canovista, sino con otro liderado por el general Martínez-Campos y con Francisco Silvela en el Ministerio de la Gobernación, con la misión de contener la presión gubernativa y ayudar a que se activara el sufragio como realidad espontánea. Ambos continuaban el plan primigenio de Cánovas. El jefe conservador no inventó el turno de partidos, ni concebía por entonces una alternancia pactada al margen del sufragio. Precisamente porque Cánovas aspiraba a aclimatar en España el gobierno parlamentario a la inglesa, pensaba que solo una derrota en las elecciones o en una votación parlamentaria podría justificar que el Rey retirara su confianza al Ejecutivo y llamara a otro partido a gobernar $^{7}$. Había que recuperar aquel cuerpo electoral que en España había derrotado al partido en el gobierno en las elecciones parciales de determinados distritos, las by-elections que en Reino Unido aún señalaban a la Corona el momento de la alternancia, $y$ también en elecciones generales como las de 1822, 1837, 1839 y $1843^{\circ}$. En cuanto a las votaciones parlamentarias, en el XIX los partidos carecían de mecanismos explícitos de disciplina, pues aquel parlamentarismo consagraba la libertad total del diputado y el senador como presupuesto básico de su función deliberativa'. Si a eso se le suma que una parte de esos parlamentarios debía su escaño más a su arraigo en el distrito que a la ayuda que le prestaba la organización nacional, se explica la mayor libertad de voto de entonces. Los parlamentarios la empleaban contra su propio gobierno en aquellas materias en las que existía un disentimiento doctrinal o una contraposición entre el interés general y el específico de sus electores. Por ello, en la Restauración, una mayoría parlamentaria no presuponía un gobierno tan estable como para agotar los cinco años de vigencia máxima que la Constitución de 1876 atribuía por entonces a las Cámaras.

\footnotetext{
${ }^{6}$ Hummel, 2002; Lario, 1997.

${ }^{7}$ Villa García, 2013.

${ }^{8}$ DSC, 15 de junio de I880, 488I. Villa García, 20I6, pp. 32-39.

${ }^{9}$ Schmitt, 1990, pp. 43-47.
} 
El plan de Cánovas culminaba con que el gobierno parlamentario español funcionase a través de un sistema bipartidista, al que atribuía las virtudes de procurar gobiernos más estables y de civilizar la alternancia. Pensaba que un sistema de dos grandes partidos nacionales disciplinaría a los políticos españoles y acabaría con el acoso al que una multiplicidad de facciones había sometido a la Corona, antes de 1875, para que les otorgara el poder. La experiencia de los años del reinado de Isabel II y la del Sexenio habían ratificado, igualmente, que la alternativa a la fragmentación tampoco podía ser un régimen servido por un solo partido político. El exclusivismo, que conducía a lo que entonces se denominaba «insurrección legal» - a la violencia de las juntas revolucionarias y los pronunciamientos militares - era un capítulo que debía cerrarse definitivamente ${ }^{10}$. Por ello, el bipartidismo se concibió como una vía media entre dos opciones que se habían experimentado sin éxito. Por supuesto, estaba también la práctica inglesa a partir de la Second Reform Act de 1867, que parecía mostrar que el gobierno parlamentario era más eficaz con dos grandes partidos capaces, por sí mismos, de ganar una mayoría que se necesitaba amplia para que las diversas votaciones y las escisiones no afectaran demasiado pronto a la estabilidad del Ejecutivo". De ahí el empeño de Cánovas en que a su Partido Liberal-Conservador le surgiera una alternativa unificada de izquierda liberal. Esta finalmente cuajaría alrededor del Partido Constitucional de Práxedes Mateo Sagasta, que reunificó en una sola formación política, llamada Partido Liberal-Fusionista, a casi todos los partidos que habían formado en la coalición de septiembre de 1868, y a la que se unieron pequeños grupos desprendidos de los conservadores y los moderados. Con todo, y como registraría con preocupación Galdós, todavía en 1883 surgió un partido de Izquierda Dinástica con ínfulas de sustituir a los sagastinos, de modo que el esquema bipartidista solo se consolidaría en las vísperas del fallecimiento de Alfonso XII.

Lo que no cuajó fue la alternancia a la inglesa, regulada a través de los resultados electorales y las votaciones parlamentarias. En España las elecciones quedaron relegadas a sancionar una alternancia previamente pactada por los conservadores y los liberales. Eso obedeció a la aspiración de Sagasta, unida ya la izquierda constitucional, de acceder al poder por la sola decisión de Alfonso XII'2. En junio de 1880, los liberales presentaron una proposición incidental en el Congreso para defender que el rey tenía derecho de cambiar, por propia iniciativa, al presidente del Gobierno y a los ministros en virtud del artículo 54.9 de la Constitución, y que era precisamente esa prerrogativa la que garantizaba la estabilidad

\footnotetext{
10 DSC, 8-11I-1876, 31।.

II Dardé, 1991.

12 Arranz Notario, 201 I, p. 597.
} 


\section{LOS FUNDAMENTOS POLÍTICOS DE LA RESTAURACIÓN}

de las instituciones. Justificaban su teoría en que, si no se interpretaba así la Constitución, la alternancia se hacía imposible, pues en España los gobiernos siempre ganaban las elecciones y disfrutaban, además, de numerosos recursos para mantener la cohesión parlamentaria. ${ }^{13}$ Cánovas disintió del diagnóstico y, en todo caso, advirtió que si los gobiernos caían sin perder antes el apoyo de la mayoría parlamentaria o de la opinión pública, y si los partidos limitaban sus aspiraciones a ganar las elecciones únicamente desde el poder, los mecanismos que procuraban la alternancia en los países parlamentarios no se activarían en España por mucho tiempo ${ }^{14}$.

La negativa de Cánovas y su partido a someterse al criterio de los liberales no prevalecería. La presión de estos últimos, que se sustentaba además en la necesidad de los recursos del poder para estabilizar la estructura de su partido y ampliar sus efectivos, no se limitó al debate parlamentario. Conminaron a Cánovas para que dimitiera y dejara «franca» la "prerrogativa regia», primero con una retirada parlamentaria y luego reuniéndose, a comienzos de $188 \mathrm{I}$, con militares díscolos y con los dirigentes republicanos, unos movimientos que parecían retrotraer a España a las conspiraciones que llevaron a la «Gloriosa» revolución de 1868 . Por ello, Alfonso XII decidió en febrero de $188 \mathrm{I}$ retirar la confianza a los conservadores y llamar al poder a los liberales, sin que los primeros hubieran sufrido una derrota electoral o parlamentaria ${ }^{15}$.

Con este primer «turno» se adquirió la paz civil y supuso el definitivo ingreso de la coalición septembrina dentro de la monarquía constitucional. Además, sería el origen de las convenciones, aceptadas por los conservadores para eludir toda ruptura política, que regularían la alternancia entre los dos partidos de la Restauración, y que se irían perfilando en sucesivas crisis. Al margen de una derrota electoral o parlamentaria $\circ$, conectado a ambas, de una escisión que mermara cualitativa o cuantitativamente su mayoría, el partido en el poder debía dejar paso a la oposición constitucional cuando esta estuviera listo para gobernar y requiriera activamente el poder. Se consideraba que un partido estaba en disposición de gobernar si previamente se había curado de sus escisiones y había logrado la suficiente fuerza y cohesión en torno a un liderazgo sólido como para recoger con garantías el decreto de disolución de las Cortes y ganar unas elecciones que aseguraran el refrendo parlamentario a ese cambio de gobierno. Se entendía por tanto que, en virtud del sistema de la doble confianza, la Corona no

\footnotetext{
13 DSC, 14 de junio de $1880,4782-4783$ y 4786 ; y 15 de junio de 1880 , 4868-4872.

14 DSC, 15 de junio del880, 4880-4884; y 16 de junio del880, 4910. Un análisis de este debate, en Arranz Notario, 201 I, pp. 598-601.

${ }^{15}$ Fernández Almagro, 1972, pp. 366-367.
} 


\section{ROBERTO VILLA GARCÍA}

debía en condiciones normales iniciar una alternancia que luego no pudiera obtener la sanción de las nuevas Cortes. Para activar la alternancia, el requerimiento del poder por parte de la oposición constitucional debía ser explícito. Este se transparentaba en el endurecimiento de la fiscalización parlamentaria al gobierno, que podía llegar a la obstrucción e incluso a la retirada de las Cortes o la amenaza de hacerlo, con objeto de indicar a la Corona que estaba en riesgo el pacto anudado entre los dos grandes partidos para asegurar la continuidad de gobierno dentro de la monarquía constitucional ${ }^{16}$.

Aunque distaba de ser un mecanismo democrático, las convenciones del turno objetivaron de algún modo la alternancia, y desalentaron la presión directa al Rey por medio de las conspiraciones y las amenazas de motines y pronunciamientos militares, los métodos característicos antes de la Restauración. Además, los partidos del turno, conscientes de que su apartamiento del poder no sería definitivo, tenían un incentivo para colaborar entre sí en las elecciones. De hecho, se coaligaban a través del encasillado, el pacto que establecía el previo reparto de las candidaturas, de modo que el partido que no iba a gobernar renunciaba a competir en la mayoría absoluta de los distritos para asegurarle al partido en el poder un Parlamento gobernable. A cambio este tampoco competía por el número de escaños que entendía suficiente para que la «oposición de Su Majestad» pudiera fiscalizar la labor de gobierno y erigirse en futura alternativa. No era el fraude lo que explicaba las mayorías en la Restauración pues, aún presente, su efecto sobre los resultados comenzó a descender respecto de las elecciones isabelinas o las del Sexenio. La clave de los resultados estaba en la falta de competencia y en la colaboración electoral de los dos grandes partidos, que funcionaban como uno solo para los comicios ${ }^{17}$.

\section{El GaLdós NOVELISTA ANTE LA RESTAURACIÓN: LA VIDA POLÍTICA EN EL CÁNOVAS}

Benito Pérez Galdós no fue un ideólogo, menos un dogmático. Era de ideas democráticas, pero también un hombre escéptico, rasgo de carácter que le privó de un perfil político acusado. Los que le conocieron, desde posiciones políticas dispares, lo describían como un hombre tolerante, tratable, de pocas palabras y sin gusto por la polémica. Sorprendía su estrecha amistad con el novelista Pereda, católico y conservador, pero Galdós lo explicó en sus memorias: «En verdad, ni

\footnotetext{
${ }^{16}$ Tusell, 1994, pp. II8-12I.

17 Varela Ortega, 200Ia, pp. 484-500.
} 


\section{LOS FUNDAMENTOS POLÍTICOS DE LA RESTAURACIÓN}

D. José María Pereda era tan clerical como alguien cree, ni yo tan furibundo librepensador como suponen otros» ${ }^{18}$. En sus obras, y especialmente en los Episodios Nacionales, Galdós explicitó su adscripción a un liberalismo progresista rayano en el republicanismo, pero sin hostilidad hacia los distintos monarcas del XIX y el XX. El escritor fue durante el Sexenio entusiasta de Prim, pero su implicación política no sobrepasó su labor de periodista, y aún se diluyó cuando un desencantado Galdós se centró, a partir de 1873, en su prolífica labor literaria. De ella le sacó en la siguiente década su amigo y patrono José Ferreras, un periodista y diputado íntimo de Sagasta que ejerció gran influjo sobre el literato. Galdós le describió como «el hombre de mayor agudeza política» que había conocido ${ }^{19}$. Fue Ferreras el que propuso a Galdós como candidato liberal por un distrito portorriqueño, en el que salió elegido como cunero. Pero el literato se mostró más activo como cronista parlamentario que como diputado, y disuelto el «Parlamento largo» (I886-1890) se apartó de la política activa.

En la primera década del XX, Galdós se radicalizó en el contexto de la oleada anticlerical del cambio de siglo, de la que se convirtió en referente con su célebre obra teatral Electra. Como el Partido Liberal se mostraba dividido ante la cuestión, Galdós se acercó a la izquierda republicana, con la que se alineó sin ambages a partir de 1908. El literato concebía la modernidad como una revolución de tipo religioso. Consideraba que debía romperse con la tutela eclesiástica de la enseñanza y que el Estado debía convertirse en motor de una activa secularización si se quería consolidar la libertad y acelerar la convergencia de España con los países más avanzados del continente. Se mostró partidario de adaptar las políticas laicas de la tercera república francesa, y en especial la disolución de las órdenes monásticas ${ }^{20}$.

Su acercamiento al movimiento republicano, recibido con entusiasmo por un Lerroux que admiró su «valor cívico» por «divorciarse públicamente del régimen político que deshonra a España, para unirse a la causa del pueblo» ${ }^{21}$, hizo rememorar en Galdós la heterogeneidad y el cúmulo de personalismos y disonancias internas que habían lastrado la experiencia republicana de 1873. En la quinta serie de sus Episodios Nacionales no dejó de esbozar críticas al republicanismo, en especial al federal, al que atribuía con su radicalismo haber bloqueado la consecución del programa progresista en el Sexenio, y haber favorecido así indirectamente a la reacción. De ahí que en la segunda década del XX, Galdós

\footnotetext{
${ }^{18}$ Pérez Galdós, 2020, p. 22. El carácter y las ideas de Galdós, en Brenan, 1986, 397; Marrero, 197I, pp. 50-5I; Dendle, 1980; Estébanez Calderón, 1982; y Cánovas Sánchez, 2019, pp. 163-182.

${ }^{19}$ Pérez Galdós, 2020, p. 24.

${ }^{20}$ Berkowitz, 1948, p. 446; Ortiz Armengol, 1996, 649 y 686; Castro Alfín, 2020, pp. 365-368.

${ }^{21}$ Lerroux a Galdós, 17 de junio de 1908, en Archivo Casa-Museo Pérez Galdós, Colecciones Documentales.
} 


\section{ROBERTO VILLA GARCÍA}

pusiera sus esperanzas en el Partido Socialista Obrero Español y en un Pablo Iglesias al que veía como el «apóstol» de un solidarismo social que superaría el individualismo liberal. Pero las rigideces doctrinales del marxismo casaban poco con las ideas del literato, que en 1912 se asoció al más moderado Partido Reformista, un republicanismo posibilista con la monarquía que, si tenía un programa de neutralización del Estado por medio de una reforma constitucional que convirtiera la tolerancia de cultos en libertad plena, no era partidario de una secularización forzada de la sociedad. Galdós acentuó su veta posibilista cuando accedió a entrevistarse en 1913 con Alfonso XIII y se alejó de todo movimiento de oposición frontal al rey ${ }^{22}$. En realidad, su republicanismo fue más intelectual que de acción. Aunque fue elegido diputado al frente de la conjunción republicano-socialista de 1910, no se prodigó en las tareas parlamentarias. Galdós siempre confió en la virtud de la política para cambiar la realidad, pero se sentía más cómodo actuando como intelectual comprometido ${ }^{23}$ que como hombre de partido.

Esta evolución tenía que registrarse necesariamente en la obra que le ocupó casi toda su vida de literato, los Episodios Nacionales ${ }^{24}$. Cuando escribió el Cánovas, Galdós estaba ya inmerso y activo en el movimiento republicano y socialista. Por ello, su representación del «pueblo-totalidad» de la primera serie, que con la invasión francesa despierta a la virtud y aminora sus defectos atávicos gracias al patriotismo y a la difusión de la «conciencia nacional» ${ }^{25}$, o su perspectiva, liberal y moralizante pero crítica y distanciada respecto de los enfrentamientos civiles del primer tercio del XIX, dieron paso a la contraposición populista entre una oligarquía sin principios, descreída y centrada en enriquecerse por todos los medios («positivista» la denomina con ironía), y un pueblo-clase trabajadora doblemente sojuzgado por su dependencia económica y su sometimiento al oscurantismo clerical. Pero esto no derivaba solo de su nueva adscripción política. También reflejaba la creciente preocupación de Galdós por los conflictos entre capital y trabajo, que no habían sentido otros exponentes de la novela del XIX como el francés Honoré de Balzac. En todo caso, el estado de cosas que describía Galdós, la asimilación de la monarquía liberal a la imposición retardataria de una oligarquía, servía para justificar una ruptura que acercara a España al modelo republicano francés.

22 Berkowitz, 1948, p. 402; Ortiz Armengol, 1996, pp. 696-697, 719-723 y 741-745; Suárez Cortina, 2006, p. 90; Arencibia, 2020, p. 278.

${ }^{23}$ Sobre las relaciones entre intelectualidad y política en el cambio de siglo, Kurzman, 2008, pp. I I- I4; y Castro Alfín, 2020, pp. 369-370.

${ }^{24}$ Los trabajos sobre la obra de Galdós son inabarcables. Por su interés para el objeto de este artículo, Gómez de la Serna, 1954; Hinterhäuser, 1963; Regalado, 1966; Zambrano, 1982; y Muñoz Marquina, 1988.

${ }^{25}$ Canal, 2013, p. 313. 


\section{LOS FUNDAMENTOS POLÍTICOS DE LA RESTAURACIÓN}

No por ello su Cánovas deja de reflejar bien el ambiente que facilitó el retorno de Alfonso XII. España era un país «que pedía paz y orden, metiendo de una vez en cintura a los malditos carcas y a los insurgentes de Cuba». Galdós también reconoció en el hombre público que da título a su novela a alguien «digno, inteligente, culto y capaz», al que cabía respetar y aún admirar «por su elevado entendimiento, por su saber de Historia y de política, así como por su palabra enérgica y sugestiva, esmaltada con los donaires de un ingenio sutil» ${ }^{26}$. El Cánovas de Galdós es un retrato aproximado de lo que el político conservador representó en los años iniciales de la Restauración «revelando su carácter, sus preferencias, la orientación general de su política, nada persecutoria, comprensiva y humana ${ }^{27}$. Esta se explicita en la misión que Cánovas encarga a Tito $\mathrm{Li}$ viano. Debía localizar a los cabecillas del cantón de Cartagena, cuatro de ellos condenados a muerte, y hacerles saber que serían amnistiados y se les permitiría regresar a España si renunciaban a todo activismo revolucionario.

Pero a través de Tito Liviano, Galdós se presenta desdeñoso con las ofertas de trabajo que recibe del «canovismo», emancipado económicamente gracias a los sobres de dinero que recibe de Mariclío, portera de la Real Academia de la Historia y genial metáfora de su afortunada dedicación a los trabajos históricos. No quiere identificarse con la nueva situación porque, para Liviano, Cánovas también es la «reacción». Para el Galdós anciano, la monarquía constitucional de I 875 había dejado de ser una vía media, capaz de conciliar a quienes defendieron la monarquía isabelina con los revolucionarios del Sexenio. Cuando Tito Liviano tenga noticias del manifiesto de Sandhurst a través de Leonarda Bravo, su contacto con el mundillo alfonsino, en una velada en el Teatro Real, se burlará de la pretensión de Cánovas de conciliar el catolicismo y el liberalismo. Ambas ideas «rabian de verse juntas» porque el Papa había condenado el liberalismo y no se podía introducir «el alma de Pío IX en el cuerpo de Espartero». También lamentará, por boca de Mariclío, que la Restauración llegara de la mano de un «espadón», el general Martínez-Campos, y de un pronunciamiento «de las espadas impacientes» ante el que Cánovas había tenido que «doblar su orgullosa cerviz». Una reflexión ya en abierta contradicción con la exaltación galdosiana de los pronunciamientos de significación progresista, y su marcada preferencia por el liderazgo y los métodos de otros «espadones» como Espartero o Prim. Por esta vía se llegará a una apología, en la que coinciden todos los protagonistas de la novela, de la dictadura de un sucedáneo de Espartero que apuntalase la libertad y que coincide, como se verá, con una de las fases de la futura revolución republicana.

\footnotetext{
${ }^{26}$ Pérez Galdós, 1912, pp. 18 y 64-65.

${ }^{27}$ Fernández Almagro, 195I, p. 347.
} 


\section{ROBERTO VILLA GARCÍA}

Como apuntaba Segismundo García Fajardo Segis, epítome novelado del radicalismo, no había otra forma de «salvar el espacio» entre los «furores del cataclismo» revolucionario y la «normalidad fundada» en los ideales del progreso. Sin la dictadura esparteril: «¿Cómo nos defenderemos de las fieras que... caerán sobre nosotros ansiosas de devorarnos?». El Cánovas ratificaba las apreciaciones de las novelas de la tercera y cuarta series, escritas a principios del XX. El «invencible Espartero» y Prim se alzan como los hombres públicos más relevantes del XIX galdosiano, sin que la postergación del primero y el bloqueo del proyecto político del segundo, perceptible antes de su asesinato, matizaran las loas ${ }^{28}$.

Galdós valora que Cánovas apostara por la derrota de los carlistas, sin darles tregua: «Venceremos, señor don Tito», exclamaba jubiloso José Ido del Sagrario, un apocado maestro que hace de casero del alter ego de Galdós: «barreremos de nuestro suelo y de una vez para siempre esa escoria del retroceso, esa inmundicia del absolutismo, esa paparrucha indecente de la legitimidad ${ }^{29}$. Ido es también quien advierte la sorda lucha de Cánovas con los moderados y las dificultades del político malagueño para integrar en un mismo sistema a los isabelinos y a los revolucionarios de 1868:

está tragando mucha quina... apretado entre dos muelas cordales, pues de una parte pesan sobre él los malditos moderados, los Chestes, Moyanos y Orovios que le piden neísmo, intolerancia y tente tieso, y de otra parte le acosan los alfonsinos que vienen de lo de Alcolea y quieren franquicias, unas miajas de Soberanía Nacional y vista gorda para el libre pensamiento ${ }^{30}$

Y Cánovas se inclinaba a los segundos, pues los moderados estaban a disgusto «al ver que los primeros puestos de la Política, de la Administración y del Ejército eran arramblados por la taifa de Septiembre» ${ }^{31}$. Aparte de un grupo irreductible, los moderados acabaron disolviéndose cuando el dirigente conservador decidió convocar las primeras elecciones a Cortes por sufragio universal, reconociendo así la legalidad del Sexenio.

¿Qué le hace a Galdós entonces colocar a Cánovas en la «reacción»? Su actitud conciliadora con la Iglesia católica, que restañaba la ruptura del Sexenio. Tito Liviano recusará el paso atrás que, respecto de la libertad de cultos de 1869 , suponía la tolerancia consagrada en el artículo II de la Constitución de I876. Esta haría a los españoles «más súbditos de Pío IX que de Alfonso XII». El bloqueo canovista al retorno a la «unidad católica» o la protesta del Papa mediante un

\footnotetext{
${ }^{28}$ Las citas del párrafo, en Pérez Galdós, 1912, pp. 17, 32, 82 y 119.

${ }^{29}$ Pérez Galdós, 1912, p. 70. Sobre Ido del Sagrario como sosías de Galdós, Escobar, 1994.

30 Pérez Galdós, 1912, p. 69.

31 Pérez Galdós, 1912, pp. 83-84.
} 


\section{LOS FUNDAMENTOS POLÍTICOS DE LA RESTAURACIÓN}

breve contra esa misma tolerancia no le hacían matizar esta opinión. De hecho, Galdós culpará a Cánovas de perder una oportunidad de reintroducir, por la puerta de atrás, la libertad de cultos al condicionar el posible matrimonio de Alfonso XII con Beatriz de Inglaterra, hija de la reina Victoria, a la conversión al catolicismo de la princesa. ${ }^{32}$

A Tito Liviano le entristecía que Cánovas encomendara la libertad de cultos «a un nuevo estado de civilización» que solo el tiempo traería. Para el primero esta tesis implicaba que España subsistiría «largo tiempo bajo un poder extraterritorial que entorpece $y$ ahoga todos sus alientos, $y$ ata sus manos $y$ sus pies con el cordón dogmático», en referencia al Papa. Y esto tendría el efecto contrario de apuntalar el dominio clerical de España. Galdós trata de demostrarlo al reflejar en la novela la pasividad de Cánovas ante la profusamente descrita «invasión» de los frailes franceses expulsados de aquella República, una «plaga de insectos voraces» que iba a devastar el país ${ }^{33}$.

La cuestión de los frailes franceses también sirvió a Galdós para denunciar de paso el falso liberalismo de Sagasta, hombre de «genial astucia» y «don de gentes» pero también de «flexibilidad del ingenio y de la palabra». Vicentito Halconero, contrafigura del amigo Ferreras que tienta a Tito Liviano/Galdós a sumarse a las filas liberales, le promete atar en corto a los frailes «que vengan no más que a darse buena vida», aunque se trataría bien «a los que traigan la idea de establecer en España buenos Colegios, donde podamos dar decorosa educación a nuestros hijos». La reacción de Liviano fue considerar a Halconero ya «contagiado del negro y pestilente virus» clerical. Contradiciendo su propia historia, los liberales nada harían contra el control católico de las conciencias, al que Galdós atribuía la ignorancia y el fanatismo del pueblo, que ejemplificaba un mundo rural «copado por el carlismo» ${ }^{34}$. El novelista nunca comprendió que Sagasta se negara a emplear el anticlericalismo como la argamasa que uniera a su fraccionado partido y le permitiera tender puentes con la izquierda republicana, por entenderlo divisivo, peligroso por diluir la separación entre los defensores y los detractores de la monarquía constitucional, e incompatible con la acción de gobierno ${ }^{35}$.

Galdós concluía que los liberales se estaban entregando a los carlistas derrotados en marzo de 1876, que ya no necesitarían retomar las armas. En lugar de «resolver a rajatabla el problema Vendeano», como el novelista hace decir a Segis, «los vencedores se han traído acá las ideas de los vencidos, creyendo que

\footnotetext{
32 Pérez Galdós, 1912, pp. 132 y 154.

33 Pérez Galdós, 1912, pp. $165-166$ y 260.

34 Pérez Galdós, 1912, pp. 198, 244-245, 257 y 266.

${ }^{35}$ Devlin, 1966.
} 
con ellas consolidarán el Trono flamante ${ }^{36}$. Galdós reproducía el prejuicio histórico de los republicanos respecto de las consecuencias del convenio de Vergara en 1839: para ellos, los carlistas habían ganado, agazapados tras Isabel II y la Constitución moderada de 1845. Un prejuicio duradero pues, ya en la II República, uno de los dirigentes del PSOE que había militado junto a Galdós en el reformismo, Fernando de los Ríos, acusaría en la campaña electoral de 1933 a Alejandro Lerroux de ser el «Cánovas» que iba a entregar el régimen a la derecha católica de la CEDA como ya hizo el jefe conservador en 1875, al facilitar que los carlistas se adueñaran de la monarquía de la Restauración ${ }^{37}$.

Por todo eso, Cánovas solo era un pacificador, no un modernizador. Los elogios que Galdós le tributa no son óbice para concluir que el político conservador no estaba capacitado para ninguna gran empresa de alcance histórico. Sus conocimientos de Historia se limitaban a un coleccionismo y a una labor tan erudita como estéril, «con poca o ninguna eficacia en el arte de aplicar las sabidurías trasnochadas al vivir contemporáneo» ${ }^{38}$. Al dejar sin resolver el verdadero problema de España, el clerical, Cánovas mostraba la fatuidad del liberalismo de la Restauración, y el escaso valor de sus mecanismos constitucionales. Quizás por ello, la novela los trata con superficialidad y desinterés. Galdós no duda en introducir el turno justo en el momento fundacional de la Restauración, un anacronismo inexplicable en el autor como no se interprete en términos de publicística antimonárquica. Así, representa a Sagasta, en su mitin del Teatro Príncipe Alfonso de noviembre de 1875 , vendiendo con cinco años de antelación:

la felicidad que había de resultar del turno pacífico, del equilibrio, del balanceo metódico entre los dos elementos que diferenciaban e integraban la política general sirviendo a la nación y al rey, cada cual con su credo sin perjuicio de comulgar ambos en el ideal común, en el ideal dinástico ${ }^{39}$.

No de otra forma presenta a Cánovas que, «con derroche de lógica elocuente», contestaba las interpelaciones parlamentarias «con requerimientos a la paz y concordia en los altares de la legalidad alfonsina». Ambos llamaban a una «sensatez flatulenta», «amodorrante» y «monárquica», y con ella lograron «encastillar» a todos los liberales «en las ficciones o decorosas pamplinas que les servían de plataforma». La ficción del turno la sancionaba la ficción electoral. Galdós se abstrae de los fraudes del Sexenio y el retraimiento a cada convocato-

\footnotetext{
${ }^{36}$ Pérez Galdós, 1912, pp. 125 y 127.

${ }^{37}$ El Socialista, 24 de octubre de 1933.

38 Pérez Galdós, 1912, pp. 247-248.

39 Pérez Galdós, 1912, p. 101.
} 


\section{LOS FUNDAMENTOS POLÍTICOS DE LA RESTAURACIÓN}

ria electoral de alguna de las fuerzas políticas de aquel periodo, y endosa a Romero Robledo la «maestría en la fabricación de Parlamentos» que consagraba «la espléndida mentira de la Soberanía Nacional». Galdós reniega de su pasado en el Partido Liberal haciendo decir a Tito Liviano, ante los requerimientos de Vicentito Halconero, que odiaba el «cunerismo» y que no quería pertenecer a esos «rebaños parlamentarios» que formaba el ministro de la Gobernación «como Dios hizo al mundo, de la nada». Las elecciones y el parlamento eran una mentira porque «en España no existía representación nacional», los diputados «no expresan más opinión que la de unos cuantos señores» y en las Cortes «no reside ninguna parte de la soberanía». Galdós reduce la trabajosa conformación del sistema bipartidista a «dos manadas de hombres que no aspiran más que a pastar en el presupuesto», sin «ningún fin elevado» y que no harían nada por mejorar la suerte de España ${ }^{40}$.

Todo ello se compendia en la valoración nula que otorga a la Constitución de 1876, que había erigido una legalidad común y que, cuando Galdós escribía su novela, ya era la más duradera que había tenido España. Tito Liviano coincidía con su amigo Segis en que solo era «una edición bonita y esmerada de las coplas de Calainos» porque en realidad «todos los poderes residen en el rey y en las camarillas [sic] a las que están subordinados los jefes de las ganaderías políticas». España parecía no haberse movido de los tiempos de Fernando VII, un «estado de pérfida legalidad» que solo cancelarían con una revolución «otros hombres y otras ideas» que traerían «la política de la verdad y la justicia» y gobernarían «no para una clase escogida de caballeros y señoras, sino para la familia total que goza y trabaja, triunfa y padece, ríe y llora en este pedazo de tierra feraz y desolado, caliente y frío, alegre y tristísimo que llaman España». Su llegada la anunciaba el estado agónico del país: «Prensa, Gobierno, Partidos, altos y bajos Poderes, todo ello anuncia su irremediable descomposición ${ }^{41}$.

Las esperanzas de la renovación galdosiana pasaban por el Partido Republicano Reformista, confluencia de las fuerzas de Manuel Ruiz Zorrilla y Nicolás Salmerón sancionada en su manifiesto parisino de agosto de 1876, y que el novelista pone como ejemplo a seguir para los republicanos de principios del XX, si querían emular el éxito de sus correligionarios portugueses en 19/0. Pero la apelación a Ruiz Zorrilla y Salmerón también explicitaba la preferencia galdosiana por una alternativa distinta a la república federal de 1873 y su secuela cantonal. Esta se basaba en la proclamación provisional de la Constitución de 1869, sin los artículos sobre la monarquía, que debía erigir una república unitaria compatible con la descentralización administrativa en provincias y municipios. El manifiesto

\footnotetext{
${ }^{40}$ Las citas del párrafo, en Pérez Galdós, 1912, pp. 102, 104, 108, 197 y 236-237.

41 Pérez Galdós, 1912, pp. 130-131 y 233.
} 


\section{ROBERTO VILLA GARCÍA}

zorrillista y salmeroniano establecía que la nueva república se gobernaría mediante un «régimen provisional de dictadura» que podría suspender los derechos civiles, ese remedo galdosiano de dictadura esparteril bajo el que se renovarían primero ayuntamientos y diputaciones y se depuraría y reorganizaría a fondo el Ejército y la administración, todo ello antes de ir a unas elecciones a Cortes que reformarían esa Constitución provisional para luego funcionar como ordinarias. La defensa por Galdós del régimen de dictadura se explicaba en que serviría no solo para defender la revolución de las probables acometidas del enemigo, sino para sortear una nueva parálisis en la aplicación del programa progresista y republicano, factor al que el novelista atribuía el fracaso del Sexenio. De ahí que exaltara a un hombre con mano de hierro que, como Espartero o Prim, no se detuviera ante las minucias de la política de partidos o las maniobras parlamentarias, y al que el novelista atribuía propiedades salvíficas ${ }^{42}$.

Sucedáneo civil recipiendario de la admiración galdosiana sería Ruiz ZorriIla, al que por entonces se consideraba sucesor de Prim en el ala izquierda del antiguo Partido Progresista. En el Cánovas aparece como el «gran ciudadano rebelde y tenaz» ${ }^{43}$, que no cejaría en su empeño revolucionario contra la Restauración casi hasta su muerte en 1895. Esta exaltación tampoco era casual. Ruiz Zorrilla era, en 1912, el punto de encuentro histórico de todas las fracciones republicanas de la extinta conjunción republicano-socialista, desde Melquíades Álvarez hasta Alejandro Lerroux. Además, la coordinación de los republicanos la ejercía, como patriarca supremo del movimiento, José María Esquerdo, que había sido fiel segundo de Zorrilla.

Pero los repetidos fracasos de Zorrilla frente a la monarquía mostraban hasta qué punto las convulsiones del Sexenio y especialmente el «desventurado» año de 1873 habían hecho pagar un alto precio a la izquierda republicana. «La España que aspira a un cambio radical y violento de la política»s se había quedado «tan anémica» como la conservadora. Habrían de pasar años, «lustros tal vez, quizá medio siglo largo antes de que este régimen atacado de tuberculosis étnica sea sustituido por otro que traiga nueva sangre y nuevos focos de lumbre mental». Sin afán de profetizar, Galdós acertó al aplazar la repetición de esas convulsiones a los años treinta del XX. Eso sí, el novelista, a través de Segis, anunciaba no estar disponible para involucrarse en rupturas inmediatas, pues se presentaba seducido por «un epicureísmo que me asegure el regalo y el reposo del presente y el porvenir» ya que "quería vivir bien y sin fatigas». La apelación de Mariclío a declararse revolucionarios y «contumaces en la rebeldía» con que se cierra la

42 Artola, 1991, pp. 184-187; Pérez Galdós, 1912, p. 133.

43 Pérez Galdós, 1912, p. 71. 


\section{LOS FUNDAMENTOS POLÍTICOS DE LA RESTAURACIÓN}

novela no concernía ya a Galdós, sino que interpelaba a las generaciones más jóvenes ${ }^{44}$.

\section{LA ReSTAURACIÓN DEL GALDÓS CRONISTA.}

Este Galdós doliente, converso a la crítica regeneracionista de la Restauración y al diagnóstico republicano de que los problemas de la modernidad se solventaban con un proceso revolucionario tan profundo como el francés de 1789, contrasta sin embargo con el Galdós del último cuarto del XIX, que valoraba la paz en libertad que la monarquía constitucional parecía haber consolidado. Cronista parlamentario avezado durante el Sexenio, Galdós había accedido a desgana y por motivos económicos a retomar el género y enviar unas crónicas en novedosa forma de carta a La Prensa de Buenos Aires. Las crónicas más políticas se concentraron en el periodo de 1883 a 1887 , mientras que se hicieron más literarias y costumbristas a partir de ese año. El hecho de que se publicaran en Argentina explica que los españoles solo conocieran al Galdós crítico con la Restauración de los Episodios Nacionales. Sin embargo, en contraste con el Cánovas, las crónicas galdosianas se caracterizaron por su carácter sereno y circunspecto, y aunque más favorables a los liberales de Sagasta, no se rebajaban a panfleto partidista.

La adscripción de Galdós al Partido Liberal de la mano de Ferreras subrayó su desengaño con la política anterior a $1875^{45}$. Había sido de tal calibre que mantuvo, pese a su significación de izquierda, una expectativa benévola respecto a los gobiernos de Cánovas. En sus crónicas siempre expresó su desacuerdo con el jefe conservador porque le parecía umuy conservador, demasiado conservador en todo». Pero al mismo tiempo Cánovas también aparece como el político más elogiado: «maestro consumado en las lides parlamentarias», «estadista insigne», de «grande autoridad» y «realmente extraordinario por la variedad y alteza de sus talentos», pues «pocos como él han dominado y practicado el arte del Gobierno». En definitiva, Cánovas era para Galdós el «hombre más notable de España en los modernos tiempos» ${ }^{46}$, apóstrofes que no obtuvo su jefe Sagasta, pese a que no le escatimó el reconocimiento de sus dotes políticas y de tribuno.

La más importante era la capacidad sagastina, no igualada por otro líder de la izquierda constitucional, de conjurar una y otra vez los efectos de la división faccional del Partido Liberal. Para un lúcido Galdós, era precisamente este estado

\footnotetext{
44 Pérez Galdós, 1912, pp. 237-238.

45 Milán García, 2003.

46 Pérez Galdós, 1923, III, pp. 179, 181 y 183; y IV, p. 15.
} 
de división permanente, que se arrastraba desde los tiempos del Partido Progresista, el que había inutilizado a la izquierda liberal como instrumento de gobierno en sus periodos de mando. A este problema, que amenazaba también con cuartear la primera situación liberal de la Restauración, dedicaría Galdós la primera de las crónicas recopiladas por Ghiraldo tres años después de la muerte del novelista, criticando la aparición de la Izquierda Dinástica que desplazó a Sagasta del poder en octubre de 1883. El novelista coincidía con Cánovas en que la faccionalización y el exclusivismo de partido estaban conectadas a una demanda de reforma constitucional, la de reinstaurar la Constitución de 1869, que le parecían un artificio para justificar ambiciones de poder:

Cualquier extraño creería que nos hallamos en los albores de la civilización y que no poseemos el archivo de Constituciones más variado y precioso que en el mundo existe. Sobre la peor de las que tenemos podríamos fundar el derecho público y administrativo más perfecto y más práctico que en lo humano cabe... Pero, no; es preciso hacer una Constitución nueva. ¿Qué se diría de un partido que no tuviera la suya, del mismo modo que cada individuo tiene su sombrero? ${ }^{47}$

Esas disputas causaban a Galdós «asombro y pena» porque en España ya se gozaba «de tanta libertad como el Estado más libre de Europa, sin excluir la República francesa», y había que concentrarse en los problemas económicos, educativos, administrativos y militares, $y$ en consolidar una Hacienda «llevada por la constancia y el orden a un estado de relativa prosperidad» pero que no era inmune a la inestabilidad política. En España el supuesto problema constitucional se reducía a la disputa ya crónica por el liderazgo de la izquierda constitucional, ahora polarizada entre Sagasta y Posada Herrera. Desaparecido el veto regio para que los progresistas gobernaran con la monarquía, las ambiciones de sus políticos más conspicuos constituían los verdaderos «obstáculos tradicionales» ${ }^{48}$.

Galdós aprovechaba la crítica para defender el bipartidismo a la inglesa entre liberales y conservadores, y criticaba el propósito del ala radical de aquéllos de anular a estos últimos. Una derecha constitucional robusta era el requisito previo para una izquierda constitucional robusta. Sin los conservadores, vaticinaba que el «heterogéneo partido liberal se quebraría en mil pedazos», víctima «del fraccionamiento y de las pasiones de sus propios hombres» ${ }^{49}$. El bipartidismo no solo mejoraba la disciplina. También desterraba el exclusivismo y suavizaba las rivalidades, hasta el punto de reducir la enemistad personal al disentimiento político. La Restauración había traído, según Galdós:

\footnotetext{
47 Pérez Galdós, 1923, III, pp. 8 y 10-1I.

48 Pérez Galdós, 1923, III, Pp. 12 y $16-17$.

49 Pérez Galdós, 1923, Iv, p. 96.
} 


\section{LOS FUNDAMENTOS POLÍTICOS DE LA RESTAURACIÓN}

en el terreno privado... una dichosa fraternidad entre los que se pasan la vida politiqueando. Y lo que no hace la fraternidad que a veces también falta, hácelo la buena educación. En otro tiempo, los moderados y progresistas no se hablaban privadamente ${ }^{50}$

Con todo, la mejora del ambiente parlamentario no había repercutido en la eficacia del Parlamento mismo. Como en los Episodios, Galdós no dudaría en criticar el «pugilato de retóricas en las cuales, si abunda elocuencia y doctrina, rara vez hay que admirar la sobriedad práctica». La acción gubernativa se ahogaba «en un diluvio de palabras» y entre los liberales los había «que no ven ya con simpatía» ese parlamentarismo «y desean su radical reforma». Eso sí, la alternativa no eran los hombres con mano de hierro, sino el Parlamento mismo «aunque se hable con exceso porque el silencio empeora siempre todos los asuntos» y porque «cuestiones amenazadoras» quedan reducidas a «muy poca cosa en cuanto se les ha sometido a una discusión como las que aquí se usan» ya que «no hay quien iguale a nuestros oradores en lo de apurar un tema: lo desentrañan, lo vuelven del revés, lo examinan a todas las luces posibles, lo exprimen y le sacan toda la sustancia». Pese a la «infecundidad legislativa», no podía negarse al parlamentarismo español «la gran ventaja de la fiscalización», pues con esta y el prerrequisito de la publicidad, Galdós sentenciaba que «todo se sabe; no hay, no puede haber misterios en el Gobierno» y gracias «a la luz que arroja sobre todo» no había «error que pueda prevalecer» ${ }^{51}$.

Esta reflexión permite al novelista dar en la tecla de la única solución posible dentro del régimen constitucional para ir convirtiendo el Parlamento no solo en órgano deliberante y fiscalizador, sino también en legislativo: la reforma de los reglamentos de las Cámaras, con el fin de recortar los debates interminables y las múltiples posibilidades que otorgaban a los grupos de oposición para obstruir la labor de gobierno ${ }^{52}$.

El Galdós de entonces no solo era un firme defensor de los logros de la política de la Restauración, sino también del desempeño personal de los monarcas, tanto de Alfonso XII como especialmente de la regente María Cristina de Habsburgo:

A nadie se le ocurría que la archiduquesa pudiera desplegar, andando el tiempo, las raras dotes de un soberano constitucional, que lleva sobre sus hombros la

\footnotetext{
50 Pérez Galdós, 1923, I, p. 179.

51 Shoemaker, 1973, pp. 236-237; Pérez Galdós, 1923, III, pp. 25, 132, 263-264 y 267; y 1923, I, pp. 209 y 230.

52 Pérez Galdós, 1923, IV, pp. 87-88; y I, p. 209.
} 


\section{ROBERTO VILLA GARCÍA}

pesada carga del Poder Supremo con las inmensas dificultades que el ejercicio de la prerrogativa regia tiene entre nosotros ${ }^{53}$.

Ello llevaba al literato a decretar la muerte de las «camarillas», pues como buena monarca constitucional, «la Reina no habla de política más que con los ministros ${ }^{54}$.

Su tratamiento de las elecciones resultaba matizado y empírico. El problema español era el de «toda región latina» que «rara vez ofrecen el verdadero resultado de la intervención del país en su propio gobierno», si bien España destacaba por haber obtenido «hasta ahora menores ventajas» del sistema electoral. Pero el problema fundamental no estribaba en las ilegalidades, que para Galdós eran la sola secuela de que en las elecciones participaban en exclusiva «los que de una manera u otra sacan partido de las amistades y servicios políticos». La clave era que «la mayoría de la nación» se abstenía. Las artimañas «valen de poco» cuando el electorado votaba «lleno de entusiasmo y con esperanzas de una ruidosa y gallarda victoria». Como esto no se producía, «no hay Gobierno que no saque mayoría en el número y forma que más le cuadra» y le obligaba a intervenir incluso para procurar Cortes pluripartidistas, «no pudiendo marchar bien el sistema sin oposición ${ }^{55}$.

La pertenencia de Galdós al Partido Liberal le vedaba equiparar su gestión electoral con la de los conservadores. Mientras los métodos de Romero Robledo eran para el novelista «una verdadera escuela de corrupción política», opinaba que Sagasta y su «gran elector» Venancio González se comportaban con corrección y hasta eran «dignos de lástima» por verse sometidos al «martirio a fuego lento» provocado por la «avalancha de candidatos solicitando apoyo» ${ }^{56}$. La disociación era artificiosa, pues el mismo Romero había sido mano derecha de Sagasta cuando este organizó dos elecciones del Sexenio.

Pese a esto, el análisis galdosiano de los comicios del periodo es uno de los más ajustados, analíticos e imparciales con los que puede contar el historiador. En una de sus mejores crónicas, «El encasillado y sus consecuencias», Galdós refleja el cerco al gobierno de los distintos candidatos para obtener favores individuales o mejoras colectivas con las que presentarse en su distrito, y los problemas de cohesión del partido cuando dos candidatos de idéntica disciplina se disputaban el mismo escaño. Refiere de forma precisa cómo el ministro de la Gobernación ajustaba el encasillado seleccionando a los «candidatos de verdad»,

\footnotetext{
53 Pérez Galdós, 1923, III, Pp. 248-249.

54 Pérez Galdós, 1923, III, pp. 248-249.

55 Pérez Galdós, 1923, III, pp. 19-21 y 38.

56 Pérez Galdós, 1923, III, Pp. 33-34, 126 y 132.
} 


\section{LOS FUNDAMENTOS POLÍTICOS DE LA RESTAURACIÓN}

esto es, a los capaces de suscitar más apoyo entre las organizaciones electorales, además de a los que destacaban por sus dotes personales para la política nacional o por haber contribuido a reforzar la estructura del partido. El encasillado también funcionaba como mecanismo de disciplina parlamentaria, en tanto que en esa selección se relegaba en lo posible a los díscolos, que podían provocar escisiones en el grupo parlamentario ${ }^{57}$. Inmejorable es la pincelada con la que Galdós describe la existencia de una relevante lucha por el voto aun bajo el sufragio censitario:

Y no hablemos de los discursos que [el candidato] se ve obligado a echar todos los días, hablando de su consecuencia y prometiendo villas y castillos al distrito. Este va a ser muy pronto cruzado de carreteras; se construirá un Hospital, y hasta una Plaza de Toros, si es preciso. Se rebajarán las contribuciones, y se establecerá una administración subalterna para que haya muchos empleados y corra el dinero. Nada digo de las comilonas que el infeliz candidato tiene que pagar de su bolsillo para sostener los ánimos de los electores que vienen de lejos, nada más que a poner su cédula en las urnas. Actualmente, las elecciones siempre cuestan dinero ${ }^{58}$.

El colofón del análisis es una de las definiciones más precisas del fenómeno del caciquismo. Para Galdós este no era ni más ni menos que «el entronizamiento de ciertos individuos en las localidades, los cuales, como instrumentos del diputado, son dueños de los resortes administrativos». En consecuencia, su poder se basa en que:

El cacique da y quita los míseros empleos que disfrutan los más pobres del pueblo; suyos son el cartero-peatón, el secretario del Ayuntamiento, el peón caminero, el expendedor de efectos estancados. El cacique es quien al hacer el reparto de contribución, carga la mano al adversario, aliviando al amigo, de lo que se originan disgustos mil, $y$ a veces porrazos y hasta puñaladas. Verdad que el tirano de la aldea, que tan grandes servicios presta al diputado, sometiéndole la localidad, agobia a este con sus exigencias, hasta el punto de que muchos representantes del país reniegan de la hora en que se metieron en tales líos $^{59}$.

Pero Galdós no se limita a la requisitoria moralista. Entiende que «nuestras costumbres políticas no se han perfeccionado lo bastante para llegar al «desiderátum» de que el país elija libremente a sus representantes». Eso hacía necesario que el gobierno ejerciera «cierta influencia sobre los comicios» para conformar mediante el encasillado un Parlamento gobernable y evitar su antítesis, que no

\footnotetext{
57 Pérez Galdós, 1923, III, pp. 127-128.

58 Pérez Galdós, 1923, III, pp. 129-130.

59 Pérez Galdós, 1923, III, Pp. I30-131.
} 


\section{ROBERTO VILLA GARCÍA}

era la democracia sino «lo que vulgarmente se llama un "ciempiés", o en otros términos una Cámara con la cual sería imposible todo gobierno». Para Galdós la cuestión estribaba en cuál era «el grado en que esta influencia se ha de ejercer» que era «lo que determina la mayor o menor pureza de las elecciones», y que en el estadio actual de politización de España se reducía a la mayor o menor «discreción» de esa influencia gubernativa ${ }^{60}$.

Así las cosas, y en medio de la difícil coyuntura de la Regencia, Galdós se cuidaba de aclarar que no había alternativa mejor a lo existente, y menos la servida por una revolución. No creía ya que fueran a repetirse «los trastornos a que debemos una triste fama en el mundo», porque no encontraba lógica una revolución «enfrente de situaciones tolerantes como la presente, y que respeta todos los derechos y ha hecho prácticas todas las libertades». No había otra época en que «los derechos políticos hayan estado más firmemente garantidos», hasta el punto de que «la prensa goza franquicias que no ha tenido jamás entre nosotros». Refiriéndose al Sexenio y especialmente al año 1873 destacaba que, si por entonces, «cualquier periódico monárquico hubiera escrito de la República y de los republicanos lo que éstos escriben hoy de la monarquía y de los monárquicos, a sus infelices redactores no les habría quedado un hueso sano» ${ }^{61}$.

El contraste de las crónicas con el Cánovas es especialmente significativo en lo que respecta a los republicanos. En ellas refleja la heterogeneidad doctrinal y el carácter atomizado de un movimiento que, salvo en breves periodos, nunca lograba constituir un partido unificado: «Dejarían de ser españoles estos caballeros», admitía socarrón, «si se agruparan bajo los pliegues de una sola bandera, y obraran con arreglo a un solo principio de acción». La llegada de la Restauración no había estimulado su reagrupamiento. Las disputas internas entre los republicanos y su fragmentación se habían agravado, y bloqueaban su capacidad de erigirse en alternativa a los partidos monárquicos ${ }^{62}$.

De entre las diversas tendencias, Galdós simpatizaba con Castelar, que personificaba la república «posible» y la única «probable», mientras Pi y Margall era un ideólogo «divorciado de la realidad» con «masas numerosas y apasionadas, que de fijo no saben lo que quieren ni adonde van ${ }^{63}$. Ruiz Zorrilla le parecía un hombre más de «acción» que Castelar y $\mathrm{Pi}$, pero también un «sectario furibundo» empeñado en establecer la república «a todo trance» por un pronunciamiento militar y que mantenía obstinado «su ostracismo» porque, ausente de España, su prestigio «depende del misterio en que se envuelve». Galdós se explicaba que

\footnotetext{
60 Pérez Galdós, 1923, III, Pp. 124- 125.

${ }^{61}$ Pérez Galdós, 1923, III, Pp. 133 y 140-141.

62 Pérez Galdós, 1923, III, Pp. III y 274.

63 Pérez Galdós, 1923, III, Pp. II2-II3.
} 


\section{LOS FUNDAMENTOS POLÍTICOS DE LA RESTAURACIÓN}

Salmerón se hubiera separado de Zorrilla, cancelando el Partido Republicano Reformista de 1876 y declarándose partidario de la lucha legal, pues Ruiz Zorrilla pretendía una «República de partido traída, fundada y sostenida por los republicanos de una manera exclusiva», que al novelista le parecía «la calamidad más grande que podríamos imaginar» ya que conllevaría «la dictadura» ${ }^{64}$. Galdós criticaba la incongruencia de don Manuel de anunciar que su revolución iba a alumbrar una república conservadora, una contradicción flagrante entre el método y los fines:

Lo que no se dice es qué procedimientos se emplearán con los que al día siguiente del triunfo quisieran ser tan revolucionarios como antes, aspirando a variar radicalmente la organización política, social y económica del país. ¿Qué fuerza moral tendría el señor Ruiz Zorrilla para reducirlos a la obediencia? ¿De dónde saca que se le había de acatar y venerar como fundamento y defensor de la autoridad, habiendo empleado la mayor parte de su vida en burlarla y escarnecerla? ${ }^{65}$

Galdós expresaba su hartazgo hacia los pronunciamientos: «Me repugnan tanto y me son tan odiosos los movimientos militares que quisiera ocuparme de ellos lo menos posible, pues me duele consagrarles la atención, aunque sea para condenarlos». Ante la insurrección republicana de Villacampa (I886) concluyó que había que liquidar la «glorificación de la figura de Riego como defensor de las libertades y de los fueros del pueblo», pues «todas las sediciones son vituperables» y había que «condenarlas todas en absoluto si ha de haber algún día disciplina militar». Riego aún podía excusarse con Fernando VII, pero ahora España vivía en libertad $y$, en ese contexto, «emplear la violencia cuando la legalidad ampara a todo el mundo, cuando la tribuna garantiza todas las opiniones y la Prensa goza de amplia libertad» lo consideraba «criminal y contrario a toda sana política». Debía desterrarse la época en que los caudillos militares se erigían «en poder regulador» mediante sediciones «cuyo único objeto era obligar a la Corona a un cambio de gobierno» ${ }^{66}$. Para Galdós, España había entrado en un sistema de política civilizada incompatible ya con la era de los pronunciamientos:

Nuestro país, tan conmovido en los últimos años, ha adquirido una experiencia preciosísima. Cada vez se paga menos de relumbrones, detesta el romanticismo político, la fraseología hueca y las promesas locas, y sabe sentir la realidad. El sentimiento de la realidad es la gran conquista, hecha a fuerza de caídas y reveses,

\footnotetext{
${ }^{64}$ Pérez Galdós, 1923, III, pp. I|4-1/5 y | |7-|| 9.

${ }^{65}$ Pérez Galdós, 1923, Iv, p. 38.

${ }^{66}$ Pérez Galdós, 1923, III, Pp. I21, 213, 216 y 234; y IV, 257 y $260-261$.
} 


\section{ROBERTO VILLA GARCÍA}

tras penosos ensayos y pruebas de todas clases. Con tal sentimiento es seguro que llegaremos, al fin, a la estabilidad tan deseada ${ }^{67}$.

\section{CONCLUSIÓN}

Dos Galdós, dos maneras de analizar la Restauración. El Galdós cronista, liberal, que escribe para el extranjero, ofrece la explicación más ponderada, donde revela su aguda capacidad analítica y su familiaridad con el cultivo de la ciencia de Clío, hasta el punto de que sus tesis forman parte hoy de la caracterización general que, con mayores o menores matices, la historiografía española ofrece sobre las bases políticas de aquella monarquía. El Galdós novelista, republicano, da rienda suelta a las inquietudes espirituales de su evolución doctrinal, sin descuidar la vis publicística que le confiere no solo su papel de intelectual comprometido, sino también su condición de patriarca de la conjunción republicano-socialista y de destacado diputado a Cortes de un movimiento de oposición al sistema político imperante.

Así debe leerse como fuente histórica el Cánovas, atendiendo a las preocupaciones no solo estéticas sino también doctrinales de un converso reciente a un republicanismo renovado por el anticlericalismo y las inquietudes regeneracionistas. Todavía en 1901, en el prólogo que Galdós escribió a la tercera edición de La Regenta de su amigo Clarín, había mandado «callar por algún tiempo» a todos esos «censores displicentes» del regeneracionismo pues, con su «crítica negativa en todos los órdenes», se había llegado «a la insana costumbre de creernos un pueblo de estériles, absolutamente inepto para todo», y al pensar demasiado en su debilidad, los españoles habían acabado «por padecerla» ${ }^{68}$. Sin embargo, solo una década después, Galdós cerraba los Episodios Nacionales con un balance no muy diferente al de la literatura regeneracionista: la construcción de la España liberal había fracasado, y no quedaba otra opción que un nuevo destejer revolucionario para recomenzar la tarea inacabada en el XIX. Con ello, el novelista cumbre de nuestra literatura contemporánea parecía renegar de sí mismo y sepultaba inconscientemente su propia obra, que quedaría en las primeras décadas del nuevo siglo como algo demodé y rancio. "Garbancero»: así resumiría Valle-Inclán con mordacidad indudable el menosprecio que la generación del 98 , con la única excepción de Maeztu, tributó a los Episodios Nacionales y al patriotismo liberal y progresista que destilaban sus cuatro primeras series ${ }^{69}$.

\footnotetext{
${ }^{67}$ Pérez Galdós, 1923, III, p. 121.

68 Marrero, 197I, pp. 238-239.

${ }^{69}$ Canal, 2013, pp. 318-32।.
} 


\section{LOS FUNDAMENTOS POLÍTICOS DE LA RESTAURACIÓN}

\section{BIBLIOGRAFÍA}

Arencibia, Yolanda, Galdós. Una biografia, Barcelona, Tusquets, 2020.

Arranz Notario, Luis, «Liberalismo y Democracia, o entre la regia prerrogativa y el voto», Historia Contemporánea, 43, 20II, pp. 585-622.

Artola, Miguel, Partidos y programas políticos 1808-1936. II. Manifiestos y programas políticos, Madrid, Alianza, I99I. Berkowitz, Hyman C., Pérez Galdós: Spanish Liberal Crusader, Madison, University of Wisconsin Press, 1948.

Brenan, Gerald, Historia de la literatura española, Madrid, Crítica, 1986.

Canal, Jordi, «Hijos de la España del siglo XIX: Benito Pérez Galdós, los Episodios Nacionales y el patriotismo», en Historia de la nación y del nacionalismo español, ed. Antonio Morales Moya, Juan Pablo Fusi y Andrés de Blas, Madrid, Galaxia Gutenberg, 2013, pp. 307-321.

Cánovas Sánchez, Francisco, Benito Pérez Galdós. Vida, obra y compromiso, Madrid, Alianza, 2019.

Castro Alfín, Demetrio, La tea y el texto. Una historia intelectual del anticlericalismo, Granada, Universidad de Granada, 2020.

Dardé, Carlos, «La democracia en Gran Bretaña. La reforma electoral de I867-I868», Ayer, 3, I99।, Pp. 63-82.

Dardé, Carlos, La aceptación del adversario: Política y políticos de la Restauración, Madrid, Biblioteca Nueva, 2003.

Dendle, Brian J., Galdós. The Mature Thought, Lexington, The University Press of Kentucky, 1980.

Devlin, John, Spanish Anticlericalism: A Study in Modern Alienation, New York, Las Américas, 1966.

Escobar, María del Prado, «La doble función de un personaje galdosiano», Philologica canariensia, 0, 1994, PP. I37-150.

Estébanez Calderón, Demetrio, «La evolución política de Galdós y su repercusión en la obra literaria», Anales Galdosianos, XVII, 1982, pp. 7-22.

Fernández Almagro, Melchor, Cánovas. Su vida y su política, Madrid, Ambos Mundos, 1951.

Fernández Almagro, Melchor, Historia Política de la España Contemporánea. I. I868-/885, Madrid, Alianza, 1972.

Gómez de la Serna, Gaspar, España en sus Episodios Nacionales, Madrid, Movimiento, 1954.

Gullón, Ricardo, Galdós, novelista moderno, Madrid, Taurus, 1987.

Hinterhäuser, Hans, Los «episodios nacionales» de Benito Pérez Galdós, Madrid, Gredos, 1963.

Hummel, Jacky, Le constitutionnalisme allemand (I8/5-19/8), París, PUF, 2002.

Kurzman, Charles, Democracy denied, 1905-1915, Cambridge, Harvard University Press, 2008.

Lario, Ángeles, «La Corona en el proyecto canovista», en Antonio Cánovas y el sistema político de la Restauración, ed. Javier Tusell y Florentino Portero, Madrid, Biblioteca Nueva, 1997, pp. 89-I I0.

Laslett, Peter, «The Wrong Way through the Telescope: A Note on Literary Evidence in Sociology and in Historical Sociology»), British Journal of Sociology, 27, 3, 1976, pp. 319-342.

Marrero, Vicente, Historia de una amistad, Madrid, Novelas y Cuentos, 1971.

Milán García, José Ramón, «Los liberales en el reinado de Alfonso XIl: el difícil arte de aprender de los fracasos», Ayer, 52, 2003, pp. 91-II6.

Muñoz Marquina, Francisco, «Los Episodios Nacionales», en Madrid en Galdós. Galdós en Madrid, Madrid, Comunidad de Madrid, 1988, pp. 25।-269.

Ortiz Armengol, Pedro, Vida de Galdós, Barcelona, Crítica, 1996.

Pérez Galdós, Benito, Cánovas, Madrid, Sucesores de Hernando, 1912.

Pérez Galdós, Benito, Obras inéditas. I. Fisonomías sociales, ed. Alberto Ghiraldo, Madrid, Renacimiento, 1923.

Pérez Galdós, Benito, Obras inéditas. III. Política española I, ed. Alberto Ghiraldo, Madrid, Renacimiento, 1923.

Pérez Galdós, Benito, Obras inéditas. IV. Política española 2, ed. Alberto Ghiraldo, Madrid, Renacimiento, 1923.

Pérez Galdós, Benito, Memorias de un desmemoriado, Madrid, Renacimiento, 2020

Regalado, Antonio, Benito Pérez Galdós y la novela histórica española, Madrid, Ínsula, 1966.

Schmitt, Carl, Sobre el parlamentarismo, Madrid, Tecnos, 1990.

Shoemaker, William H., Las cartas desconocidas de Galdós en «La Prensa» de Buenos Aires, Madrid, Cultura Hispánica, 1973.

Suárez Cortina, Manuel, La sombra del pasado. Novela e historia en Galdós, Unamuno y Valle-Inclán, Madrid, Biblioteca Nueva, 2006.

Tusell, Javier, Antonio Maura. Una biografia política, Madrid, Alianza, 1994.

Tusell, Javier y Portero, Florentino (eds.), Antonio Cánovas y el sistema político de la Restauración, Madrid, Biblioteca Nueva, 1997.

Varela Ortega, José, Los amigos políticos. Partidos, elecciones y caciquismo en la Restauración (I875-1900), Madrid, Marcial Pons, 200la. 


\section{ROBERTO VILLA GARCÍA}

Varela Ortega, José (dir.), El poder de la influencia. Geografia del caciquismo en España, Madrid, Centro de Estudios Políticos y Constitucionales, $200 \mathrm{lb}$

Villa García, Roberto, «Elecciones sin turno: los comicios a diputado de 1879», Historia Contemporánea, 46, 2013, pp. III-142.

Villa García, Roberto, España en las urnas. Una historia electoral (I8I0-20 I5), Madrid, La Catarata, 2016.

Zambrano, María, La España de Galdós, Barcelona, La Gaya Ciencia, 1982. 